\title{
The 5th Anniversary of Hurricane Katrina: Legacy of Challenges
}

\author{
Italo Subbarao, D0, MBA; Frederick M. Burkle Jr, MD, MPH, DTM; James M. Lyznicki, MS, MPH
}

T

The fifth anniversary of Hurricane Katrina provides our Disaster Medicine and Public Health Preparedness (DMPHP) readership with a stark reminder of the human cost and long-term burden of illness caused by this sentinel event. As evidenced in this issue's lead article "Children as Bellwethers of Recovery" by Abramson and colleagues, it may be surprising to some to note a significant 5 -fold rise in serious emotional disturbance in children who were exposed to Katrina compared to those who were not exposed. To many of our seasoned readers these unfortunate findings are not unexpected. Since the journal's first issue, DMPHP has chronicled, cataloged, and provided an ongoing narrative through original research articles, review articles, and commentaries on the increasing medical and public health challenges facing the USGulfCoast region. DMPHP and other peer-reviewed publications have highlighted articles examining the consequences of indirect morbidity and mortality related to a lack of access to and availability of care, chronic disease exacerbations, and mental and behavioral perturbations. As such, it is appropriate to take a step back to highlight some of the relevant articles, especially those that foreshadowed the consequences that we are continuing to see in Mississippi and Louisiana.

The inaugural issue of DMPHP contained 2 articles inextricably linked to access to care. The first, authored by New Orleans Public Health Director Dr Kevin Stephens and colleagues, showed a $47 \%$ rise in crude mortality in the New Orleans metropolitan area 6 months post-Katrina. ${ }^{1}$ The process reaching this conclusion was unique and told its own story of the importance of surveillance pre- and postdisaster. Without a surveillance system, public health loses its credibility. With the lack of a functioning surveillance system, these researchers confirmed a disturbingly increased trend in mortality by using obituary notices in The Times-Picayune as a data source. This was one of the first confirmations that the lack of access to preventive care had reared its ugly head. A second study surveyed physician displacement, revealing that a significant proportion of physicians $(24.4 \%)$ had been evacuated from the Gulf region and had not returned, despite their pleas for assistance to make this possible. This decline in availability of care was again translated inextricably into excess morbidity and mortality. ${ }^{2}$

As access and availability issues mounted, chronic disease morbidity became an additional problem, with no quick solution. The vast majority of displaced people in Hurricane Katrina were predominately African American (76\%), largely unemployed or underemployed (53\%), did not own homes (66\%), lacked health care insurance (47\%), and had chronic health conditions (56\%). Approximately half of these evacuees lacked medications at the time of displacement. Moreover, most were not able to access their medical records. A survey of 1043 displaced and nondisplaced Hurricane Katrina survivors (aged 18 years and older) found that the large majority of respondents $(73.9 \%)$ had 1 or more chronic medical conditions during the year before the hurricane. ${ }^{4}$ After the hurricane, one fifth of respondents reported a disruption in treatment of at least 1 condition. Not surprising, disruptions were greatest for people with mental disorders, followed by those with conditions such as diabetes and cancer. The fewest reports of disruption involved respiratory illness, heart disease, and musculoskeletal conditions. A 2009 University Health System study noted a 3-fold increase in patients with acute myocardial ischemia and infarction 2 years post-Katrina, postulating that psychosocial stress played a major and ongoing contributory role. ${ }^{5}$

Before Hurricane Katrina, disaster preparedness did not focus on vulnerable populations with chronic disease or requirements for long-term recovery. What has been a serious fault line in preparedness nationwide is that efforts are primarily directed at emergency response and management. With 125 million Americans living with chronic illnesses, which contribute to $70 \%$ of all deaths and one third of years of potential life lost before age 65 years, a major shift in thinking and planning in disaster preparedness and prevention must occur. Unfortunately, it rarely becomes evident until these illnesses are exacerbated by disaster-related physical, psychosocial, and environmental factors, and even then it is often overlooked or denied.

Exacerbating factors include extreme temperature and humidity changes, lack of food and water, physical and emotional trauma, and disruptions in the health and public health systems and their protective infrastructure. Population-based studies evaluating the indirect or excess mortality and morbidity that follow the direct deaths and injuries of a disaster are always preventable. Studies following large-scale disasters have demonstrated that people with chronic medical conditions, especially women, children, elderly adults, and people with disabilities, are disproportionately affected. Given that approximately $80 \%$ of adults aged 65 years or older have at least 1 chronic medical condition and about $50 \%$ have at least 2 chronic conditions, this fast-growing segment of the US population is particularly vulnerable to a disaster. The only solution is better preparedness planning, timely evacuation, and access to care strategies designed ahead of time to mitigate excess or indirect mortality and morbidity.

Mental and behavioral health surveys have also demonstrated a significant increase in the prevalence of anxiety, depression, and posttraumtic stress disorder following the storm, as well as 
a documented rise in gender-based violence, especially in hastily built mobile home communities. ${ }^{6,7}$ This special issue of DMPHP contains additional evidence for a 5 -fold increase in serious emotional disturbances 5 years posthurricane. Abramson and colleagues' study and others ${ }^{8}$ add credence to widely accepted views that populations affected by natural disasters and other catastrophic emergencies experience a 5\% to $40 \%$ increased prevalence of mental and behavioral illness arising from significant human, economic, and social protection losses.

The original paper-dependent surveillance system in New Orleans turned into pulp by the hurricane-induced flooding of warehouses. This event served as reminder of how often bureaucratic attempts to update this system to an electronic format had failed. Unfortunately, current attempts to finally provide an electronic system have again failed, when public health proposals were budgeted but not funded. The ongoing crisis in psychiatric care, although problematic before the storm, is in even worse shape today. Patients are not receiving care, lingering in emergency departments for days, and possibly bouncing between several local hospital services before being transported to a psychiatric facility several hours outside the city. Five years past the storm, New Orleans's inpatient psychiatric bed capacity remains significantly compromised and woefully inadequate. Charity Hospital, the city's largest provider of inpatient psychiatric beds, remains closed. ${ }^{9}$ It was hoped that this second follow-up issue would be the final bookend to this tragedy, but both history and current events tell us otherwise.

The United States is a country with a reputation for responding rapidly to the most globally aggressive crises nature and humans have to offer. We pride ourselves on these accomplishments, the response to the Haitian earthquake being just 1 of several recent examples. Unfortunately, despite good evidence to the contrary, we remain emergency-phase junkies. Our discipline of DMPHP must incorporate evidence-based findings for change and political force. The movement has, in many ways, been launched by DMPHP and other journals such as Prehospital and Disaster Medicine, who, in partnership, work hard to both inform and kindle change. It has become a social movement of sorts that is not slowing down. If we are serious about the transition to a recognized discipline, then our primary goal must be to redirect our education, training, and operational efforts to preparedness, prevention, and broad-based recovery.

Evidence-based disciplines have a responsibility to accelerate and promote changes in policy, practice, and public health. We serve the community that has supported our professional initiatives and given us an academic home and a place to practice medicine. Unfortunately, we continue to promote various iterations on the same emergency responses that were first published decades ago. The proof in the pudding for any discipline is to show how accomplished studies (published in this journal and more than 700 others globally) can translate into effective ways to mitigate and decrease mortality and morbidity related to major crises. The engineering community a number of decades ago managed to help legislate major changes on how buildings are built in earthquake-prone areas. This led to a major decline in both direct and indirect mortality and morbidities. Why, we must ask, have all of the lessons learned and the studies performed not catalyzed a major shift in defining what disaster care and recovery is really about? It was stated in the 1970s that "disasters, for all communities, immediately define the public health and expose its vulnerabilities." 10 We know only too well our communities' vulnerabilities and can today accurately predict both the direct and indirect outcomes of any major disaster. Yet the coordination and cooperation needed to effectively redefine priorities, especially at the political and policy levels, has failed miserably. We will never define success or effectiveness in disaster management nor identify ourselves with a disaster discipline without controlling the preventable. Disaster medicine and public health preparedness are defined by the indirect and excess mortalities and morbidities they produce, and often them alone.

Authors' Affiliations: Dr Subbarao is Director, Public Health Readiness Office, American Medical Association; Dr Burkle, a Woodrow Wilson International Scholar, is Senior Fellow, Harvard Humanitarian Initiative; and $\mathrm{Mr}$ Lyznicki is Senior Scientist, Center for Public Health Preparedness and Disaster Response, American Medical Association.

Correspondence: Address correspondence and reprint requests to Dr Italo Subbarao, American Medical Association, 515 N State St, Chicago, IL 60654 (e-mail: italo.subbarao@ama-assn.org).

Received for publication: Received for publication August 9, 2010; accepted August 10, 2010.

Authors' Disclosures: The authors report no conflicts of interest.

\section{REFERENCES}

1. Stephens KU Sr, Grew D, Chin K, et al. Excess mortality in the aftermath of Hurricane Katrina: a preliminary report. Disaster Med Public Health Prep. 2007;1(1):15-20.

2. Madamala K, Campbell CR, Hsu EB, Hsieh YH, James J. Characteristics of physician relocation following Hurricane Katrina. Disaster Med Public Health Prep. 2007;1(1):21-26.

3. Greenough PG, Lappi MD, Hsu EB, et al. Burden of disease and health status among Hurricane Katrina-displaced persons in shelters: a populationbased cluster sample. Ann Emerg Med. 2008;51(4):426-432.

4. Kessler RC; Hurricane Katrina Community Advisory Group. Hurricane Katrina's impact on the care of survivors with chronic medical conditions. J Gen Intern Med. 2007;22(9):1225-1230.

5. Gautam S, Menachem J, Srivastav SK, Delafontaine P, Irimpen A. Effect of Hurricane Katrina on the incidence of acute coronary syndrome at a primary angioplasty center in New Orleans. Disaster Med Public Health Prep. 2009;3(3):144-150.

6. Anastario M, Shehab N, Lawry L. Increased gender-based violence among women internally displaced in Mississippi 2 years post-Hurricane Katrina. Disaster Med Public Health Prep. 2009;3(1):18-26.

7. Abramson D, Stehling-Ariza T, Garfield R, Redlener I. Prevalence and predictors of mental health distress post-Katrina: findings from the Gulf Coast Child and Family Health Study. Disaster Med Public Health Prep. 2008;2(2):77-86.

8. Galea S, Brewin CR, Gruber M, et al. Exposure to hurricane-related stressors and mental illness after Hurricane Katrina. Arch Gen Psychiatry. 2007; 64(12):1427-1434.

9. Mehmood SA. An Assessment of Inpatient Psychiatric Beds in the New Orleans Metropolitan Area. http://www.cityofno.com/Portals /PublicAdvocacy/Resources/FINAL_REPORT_Psych_Beds.pdf. Published March 24, 2010. Accessed August 16, 2010.

10. Burkle FM, Rupp G. Hurricane Katrina: disasters keep us honest. Monday Dev. 2005;23:5. 